\title{
The association between filial piety and loneliness among Chinese older adults in the greater Chicago area
}

\author{
XinQi Dong, Manrui Zhang, E-Shien Chang \\ Rush Institute for Healthy Aging, Rush University Medical Center, Chicago, IL,USA
}

Received: July 28, 2015

DOI: $10.5430 /$ jer.v2n1p62
Accepted: September 28, $2015 \quad$ Online Published: October 22, 2015

URL: http://dx.doi.org/10.5430/jer.v2n1p62

\begin{abstract}
Background: Loneliness is an important health indicator for psychological well-being. This study aims to examine the association between filial piety and loneliness among Chinese older adults in the U.S.

Methods: Data were drawn from the PINE study, a population-based study of 3,159 Chinese older adults aged 60 and above in the greater Chicago area. Severity of loneliness was the dependent variable. Independent variables were the expectation and perceived receipt of filial piety, examined in six domains. Negative Binomial Regression analyses were conducted.

Results: Lower levels of perceived filial piety receipt were associated with greater severity of loneliness (Ratio of Expected Severity: 0.92, 0.91-0.94) after adjusting for socio-demographics and medical co-morbidities. Expectation of filial piety was not associated with severity of loneliness.

Conclusion: Our findings indicate higher perceived receipt of filial piety may protect older adults from loneliness. Our study suggests that cultural sensitivity need to be considered in the detection and intervention of loneliness.
\end{abstract}

Key Words: Population studies, Loneliness, Filial piety, Chinese aging

\section{INTRODUCTION}

Loneliness is a distress experience associated with psychological and social well-being. The feeling of loneliness is often caused by a lack of quality or quantity in social relationships. ${ }^{[1]}$ Older adults are prone to loneliness because diminished social networks, deteriorated physical and $\operatorname{cog}$ nitive function, and lower adaptability to life changes often accompany the aging process. ${ }^{[2,3]}$ Chronic feelings of loneliness may indicate negative health consequences including high blood pressure, worsened immune and cognitive func- tion, anxiety, depression, suicidal ideation, and subsequently, increased mortality. ${ }^{[4-9]}$

Older immigrants are especially vulnerable to loneliness since they may encounter tremendous changes in their social lives while adapting to living in another country. Many older immigrants struggle to maintain their international social connections, and further, linguistic and cultural barriers impede their efforts to establish new social networks and relationships in the host country. ${ }^{[10]}$ In particular, cultural differences can significantly contribute to loneliness. For

${ }^{*}$ Correspondence: XinQi Dong, MD/MPH, Professor, Project Coordinator; Email: xinqi_dong@ rush.edu; Address: Nursing, and Behavioral Sciences at Rush University Medical Center, Chicago, Illinois; Rush University Medical Center, Chicago, Illinois; Associate director of the Rush Institute for Health Aging; Director, Chinese Health, Aging and Policy Program, 1645 West Jackson, Suite 675 Chicago, IL 60612 USA. 
instance, when describing the subjective feeling of loneliness, older adults in western societies may emphasize the lack of connection with the broader environment. In comparison, older adults from family-oriented cultures may attach importance to intimate interactions. ${ }^{[11,12]}$ A comparative study in California of immigrants from ten ethnicity groups indicated that socio-cultural backgrounds predispose some social behaviors within a certain ethnicity group and thus may interfere with the association between immigration and social isolation. ${ }^{[13]}$

In Chinese culture, filial piety is an important virtue which defines the obligation of adult children as providing adequate support and care for their older parents. ${ }^{[14,15]}$ This tradition has guided the family care-giving practice throughout Chinese history, prescribing that adult children reciprocate care for older parents. Self-reported satisfaction towards social support is a strong predictor of loneliness, ${ }^{[16]}$ and existing literature further reveals that Chinese older immigrants rely on adult children as the most important source of social support. ${ }^{[17,18]}$ Therefore, it is imperative to consider filial piety as an important cultural factor in the investigation of loneliness. A few studies have begun to explore the associations between socio-demographic factors and loneliness, such as marital status, gender, age, education, income, living arrangement. ${ }^{[7,19]}$ However, the association between integral cultural values, such as filial piety, and loneliness remains under-investigated. To our knowledge, only one study of filial piety and loneliness has been done among older Chinese adults in mainland China. This study suggested that having children who were not filial was a risk factor of loneliness. ${ }^{[20]}$

An increasing body of literature indicates that filial piety influences the physical and psychological well-being of U.S. Chinese older adults, despite the association between filial piety and loneliness has not been well established. ${ }^{[21,22]}$ The Chinese community represents the largest and oldest Asian population in the U.S., with an estimated population of 4 million. ${ }^{[23]}$ Considering that over $80 \%$ of Chinese older adults were foreign-born and that $30 \%$ of them immigrated to the U.S. after the age of $60,{ }^{[23]}$ their conceptualization of health and intergenerational relationships is likely to adhere to traditional values. ${ }^{[24,25]}$ For instance, prior research suggested that filial piety continues to be expected at a very high level among Chinese older adults in the United States. ${ }^{[26]}$ While adult children may be more acculturated than their parents in accepting western society's ideologies of individualism, ${ }^{[24]}$ older adults may subsequently suffer from loneliness if their desire for social support from adult children is not satisfied.

The prevalence of loneliness among U.S. Chinese older adults is estimated to be $26 \%,{ }^{[27]}$ relatively high compared

Published by Sciedu Press to $19.3 \%$ among U.S. older adults aged 65 and over based on U.S. Health and Retirement Study Data ${ }^{[28]}$ and $25 \%$ among U.S. older adults aged 70 and over. ${ }^{[29]}$ A qualitative study found that a majority of U.S. Chinese older adults attributed loneliness to the absence of satisfying intergeneralization relationships ${ }^{[30]}$ calling for more research attention to set up quantitative associations between filial piety and loneliness. A better understanding of this issue can contribute to the detection of loneliness and provide suggestions for interventions geared towards reducing loneliness among the Chinese community in a culturally-sensitive approach.

In this manuscript, the study aims to examine the association between the expectation and perceived receipt of filial piety and loneliness in a community dwelling population of Chinese older adults. Our central hypothesis is that lower levels of filial expectation and perceived receipt are independently associated with greater severity of loneliness in Chinese older adults.

\section{Methods}

\subsection{Population and settings}

The Population Study of Chinese Elderly in Chicago (PINE) is a population-based epidemiological study of U.S. Chinese older adults aged 60 and over in the greater Chicago area. Briefly, the purpose of the PINE study is to collect community-level data of U.S. Chinese older adults to examine key cultural determinants of health and well-being. The project was initiated by a synergistic community-academic collaboration between Rush Institute for Healthy Aging, Northwestern University, and many community-based social services agencies and organizations throughout the greater Chicago area. ${ }^{[31]}$

In order to ensure study's relevance to the well-being of the Chinese community and enhance community participation, the PINE study implemented extensive culturally and linguistically appropriate recruitment strategies strictly guided by community-based participatory research (CBPR) approach. ${ }^{[32]}$ Over twenty social services agencies, community centers, health advocacy agencies, faith-based organizations, senior apartments, and social clubs served as the basis of study recruitment sites. Eligible participants were approached through routine social services and outreach efforts serving Chinese American families in the Chicago city and suburban areas. Out of 3,542 eligible participants, 3,159 agreed to participate in the study, yielding a response rate of $91.9 \%$.

Based on the available census data drawn from U.S. Census 2010 and a random block census project conducted in the Chinese community in Chicago, the PINE study is represen- 
tative of the Chinese aging population in the greater Chicago area with respect to key demographic attributes including age, sex, income, education, number of children, and country of origin. ${ }^{[33]}$ The study was approved by the institutional review board of the Rush University Medical Center.

\subsection{Measurements}

\subsubsection{Socio-demographics}

Basic demographic information collected included age, sex, education, annual personal income, marital status, number of children, living arrangement, years in the U.S., and years in the community. Education was assessed by asking participants the years of highest education level completed, ranging from 0 to 17 years or more. Living arrangement was assessed by asking participants how many people live in their household besides themselves and was categorized into three groups: (1) living alone; (2) living with 1-2 persons; (3) living with 2-3 persons; (4) living with 4 or more persons. Income groups were divided into four groups: (1) $\$ 0-\$ 4,999$ per year; (2) \$5,000-\$9,000 per year; (3) \$10,000-\$14,999 per year; (4) more than $\$ 15,000$ per year.

\subsubsection{Medical co-morbidities}

Participants were asked if they had been told by a doctor, nurse or therapist that they had: (1) heart disease, heart attack, coronary thrombosis, coronary occlusion, or myocardial infarction; (2) stroke or brain hemorrhage; (3) cancer, malignancy, or a tumor of any type; (4) high cholesterol; (5) diabetes, sugar in the urine, or high blood sugar; (6) high blood pressure; (7) a broken or fractured hip; (8) thyroid disease; or (9) osteoarthritis or inflammation or problems with joints. The number of medical co-morbidities was calculated by totaling the number of "yes" responses to the nine items above.

\subsubsection{Filial Piety}

The assessment was planned around six domains of filial piety, including respect, happiness, care, greetings, obedience, and financial support, based on the conceptual model proposed by Gallois and colleagues. ${ }^{[34]}$ On a five-pointscale ( $1=$ very little; $2=$ rather little; $3=$ average; $4=$ rather a lot; $5=$ very much), participants were asked how much care, respect, happiness, obedience, financial support, and greeting they expected from their children. Similarly, participants were then asked to evaluate their receipt of care, respect, greeting, happiness, obedience, and financial support ( $1=$ very little; $5=$ =ery much). The overall expectation of filial piety was calculated by summing up each expectation score of the six filial behaviors. The overall expectation ranged from 6 to 30 , with higher score indicate a higher level of filial piety expectation. Similarly, the overall perceived receipt of filial piety was calculated and the aggregate score ranged from 6 to 30 . Internal consistency reliability was 0.88 for the filial piety scale in Chinese population. ${ }^{[26]}$

\subsubsection{Loneliness}

Loneliness was assessed using a validated three-question survey derived from the Revised University of California at Los Angeles Loneliness (R-UCLA) Scale. On a three-point-scale $(0=$ hardly never; $1=$ sometimes; $2=$ often $)$, participants were asked how often they felt lack of companionship, left out of life, and isolated from others. The three-item scale measures loneliness by examining the interaction with intimate others, social others, and the broader environment. The severity of loneliness was calculated by summing up the score of the three items. The aggregate score ranged from 0 to 6 , with higher score indicating greater severity of loneliness. Participants were categorized into the "any loneliness group" if they report loneliness at any level in their responses to any of the three questions. Otherwise, they were put into the "no loneliness group". The scale demonstrated satisfactory reliability in our study sample of Chinese older adults, with the standardized alpha of $0.78 .^{[27]}$

\subsection{Data analysis}

Descriptive statistics were used to summarize sociodemographics of study sample by severity of loneliness. T-tests were used to compare differences in means of filial piety between older adults with and without loneliness symptoms. To examine the association between the expectation and perceived receipt of filial piety and loneliness, we utilized Negative Binomial Regression and controlled for potential confounding factors. Model A was adjusted for basic socio-demographic characteristics, including age and sex. The next model (model B) added additional socioeconomic variables, including education and income. In model $\mathrm{C}$, we added number of children and living arrangement to the previous model. In model D, we added years in the U.S. and years in the community. In the final model E, we furthermore included number of medical co-morbidities as a potential confounder. Moreover, all of the above models (Models A-E) tested the association between the expectation and perceived receipt of filial piety and loneliness. Ratios of Expected Severity, 95\% confidence intervals (CIs), and significance levels were reported. All statistical analyses were conducted using SAS, Version 9.2 (SAS Institute Inc., Cary, NC).

\section{RESUltS}

Of the 3,159 Chinese older adults interviewed, mean age was 72.8 years $(S D=8.3$, range $60-105)$ and $58.9 \%$ were female. 
Table 1. Socio-demographics by severity of loneliness N $(\%)$

\begin{tabular}{|c|c|c|c|c|c|}
\hline & $0(\mathrm{~N}=2,307)$ & $1-3(N=669)$ & $\begin{array}{c}4-6 \\
(\mathrm{~N}=151)\end{array}$ & $\chi^{2}$, d.f & $p$-value \\
\hline \multicolumn{6}{|l|}{ Age } \\
\hline $60-64$ & 525 (22.8) & $135(20.2)$ & 18 (11.9) & & \\
\hline $65-69$ & $488(21.2)$ & $125(18.7)$ & $26(17.2)$ & & \\
\hline $70-74$ & $445(19.3)$ & $124(18.6)$ & 33 (21.9) & & \\
\hline $75-79$ & $398(17.3)$ & $121(18.1)$ & 30 (19.9) & & \\
\hline 80 and over & 451 (19.6) & $164(24.5)$ & $44(29.1)$ & 23.3, 8 & .003 \\
\hline \multicolumn{6}{|l|}{ Sex } \\
\hline Male & $1,006(43.6)$ & $249(37.2)$ & $57(37.8)$ & & \\
\hline Female & $1,301(56.4)$ & $420(62.8)$ & $94(62.3)$ & $9.8,2$ & .007 \\
\hline \multicolumn{6}{|l|}{ Education level } \\
\hline 0 year & $126(5.5)$ & $48(7.2)$ & $14(9.3)$ & & \\
\hline $1-6$ years & $899(39.0)$ & $230(34.7)$ & 44 (29.3) & & \\
\hline 7-12 years & $820(35.6)$ & $222(33.5)$ & $57(38.0)$ & & \\
\hline $13-16$ years & $399(17.3)$ & $141(21.3)$ & $32(21.3)$ & & \\
\hline More than 17 years & $61(2.7)$ & $22(3.3)$ & $3(2.0)$ & $18.3,8$ & .02 \\
\hline \multicolumn{6}{|l|}{ Income } \\
\hline$\$ 0-\$ 4,999$ & 770 (33.6) & $212(32.0)$ & 50 (33.3) & & \\
\hline$\$ 5,000-\$ 9,999$ & $1,166(50.9)$ & $359(54.2)$ & 87 (58.0) & & \\
\hline$\$ 10,000-\$ 14,999$ & $233(10.2)$ & $65(9.8)$ & $9(6.00)$ & & \\
\hline$\$ 15,000$ - \$19,999 & $55(2.4)$ & $10(1.5)$ & $2(1.3)$ & & \\
\hline Over $\$ 20,000$ & $68(3.0)$ & $16(2.4)$ & $2(1.3)$ & $9.2,2$ & .32 \\
\hline \multicolumn{6}{|l|}{ Marital Status } \\
\hline Married & 1,768 (76.8) & $381(57.0)$ & 66 (43.7) & & \\
\hline Separated & $32(1.4)$ & $18(2.7)$ & $4(2.7)$ & & \\
\hline Divorced & 43 (1.9) & $28(4.2)$ & $2(1.3)$ & & \\
\hline Widowed & 450 (19.6) & $235(35.1)$ & 79 (52.3) & & \\
\hline Never Married & $9(0.4)$ & $7(1.1)$ & $0(0.0)$ & $170.7,8$ & $<.001$ \\
\hline \multicolumn{6}{|l|}{ Living Arrangement } \\
\hline Living alone & $400(17.4)$ & $204(30.5)$ & $66(43.7)$ & & \\
\hline Living with 1 person & $1,215(52.7)$ & $293(43.8)$ & $50(33.1)$ & & \\
\hline $2-3$ & $350(15.2)$ & $102(15.3)$ & $28(18.5)$ & & \\
\hline 4 or more & $341(14.8)$ & $70(10.5)$ & $7(4.6)$ & $113.0,6$ & $<.001$ \\
\hline \multicolumn{6}{|l|}{ Years in the U.S. } \\
\hline $0-10$ & $619(26.9)$ & $178(26.7)$ & $41(27.2)$ & & \\
\hline $11-20$ & $743(32.3)$ & $167(25.1)$ & $44(29.1)$ & & \\
\hline $21-30$ & $558(24.3)$ & $172(25.8)$ & 31 (20.5) & & \\
\hline More than 30 years & $378(16.5)$ & $149(22.4)$ & 35 (23.2) & 22.9, 6 & $<.001$ \\
\hline \multicolumn{6}{|l|}{ Years in the } \\
\hline \multicolumn{6}{|l|}{ Community } \\
\hline $0-10$ & $1,317(57.2)$ & $386(57.9)$ & $90(60.0)$ & & \\
\hline $11-20$ & $548(23.8)$ & $156(23.4)$ & $31(20.7)$ & & \\
\hline $21-30$ & $302(13.1)$ & $67(10.0)$ & $13(8.7)$ & & \\
\hline More than 30 years & $134(5.8)$ & $58(8.7)$ & $16(10.7)$ & 16.6, 6 & .01 \\
\hline \multicolumn{6}{|l|}{ Overall Health } \\
\hline Very good & $113(4.9)$ & $21(3.1)$ & $2(1.3)$ & & \\
\hline Good & $877(38.0)$ & $186(27.8)$ & 30 (19.9) & & \\
\hline Fair & 989 (42.9) & $271(40.5)$ & 54 (35.8) & & \\
\hline Poor & $328(14.2)$ & 191 (28.6) & $65(43.1)$ & $142.5,6$ & $<.001$ \\
\hline \multicolumn{6}{|l|}{ Quality of Life } \\
\hline Very good & $174(7.6)$ & $37(5.5)$ & $3(2.0)$ & & \\
\hline Good & $1,060(46.0)$ & $264(39.5)$ & $54(35.8)$ & & \\
\hline Fair & $1,020(44.2)$ & $337(50.4)$ & $81(53.6)$ & & \\
\hline Poor & $52(2.3)$ & $31(4.6)$ & $13(8.6)$ & $47.7,6$ & $<0.001$ \\
\hline \multicolumn{6}{|l|}{ Health Changes } \\
\hline Improved & $209(9.1)$ & $57(8.5)$ & $8(5.3)$ & & \\
\hline Same & $1,213(52.6)$ & $274(41.0)$ & $41(27.2)$ & & \\
\hline Worsened & $885(38.4)$ & 337 (50.5) & $102(67.6)$ & $73.5,4$ & $<0.001$ \\
\hline
\end{tabular}

Table 1 presents socio-demographics of study participants by the severity of loneliness. The severity of loneliness was differed by age $(p<.01)$, gender $(p<.01)$, educational level $(p<.05)$, marital status $(p<.001)$, living arrangement $(p<.001)$, years in the U.S. $(p<.001)$, years in the community $(p<.05)$, overall health status $(p<.001)$, quality of life $(p<.001)$, and health change over the last year $(p<.001)$. Participants who had a loneliness score higher than four were likely to be the older adults who were 70 and older $(70.9 \%)$, with educational level less than 12 years $(76.6 \%)$, and living alone or with one person $(76.8 \%)$.

Table 2 presents the means of filial piety expectation and perceived receipt by any loneliness and no loneliness. There was no significant difference in overall filial piety expectations between older adults with and without any loneliness symptom. However, when specific domains of filial piety expectation were examined, older adults with any loneliness symptoms expected a higher level of care compared to those without loneliness symptoms (Mean: $3.51 v s .3 .32, p<.01$ ). Moreover, we found older adults who reported any loneliness symptoms perceived a lower level of overall filial piety receipt (Mean: $22.65 v s .20 .80, p<.001$ ). Specifically, older adults with any loneliness symptoms perceived that they received lower levels of respect (Mean: $4.25 v s .3 .96, p<.001$ ), happiness (Mean: 3.92 vs. 3.50, $p<.001$ ), care (Mean: 3.73 vs. 3.41, $p<.001$ ), greeting (Mean: 4.08 vs 3.74, $p<.001$ ), and obedience (Mean: 3.85 vs 3.41, $p<.001$ ).

Table 2. The expectation and perceived receipt of filial piety by loneliness

\begin{tabular}{lllll}
\hline & $\begin{array}{l}\text { No loneliness } \\
\text { Mean }(\boldsymbol{S D})\end{array}$ & $\begin{array}{l}\text { Any loneliness } \\
\text { Mean (SD) }\end{array}$ & $\boldsymbol{t}$ & $\boldsymbol{p}$-value \\
\hline Filial Piety Expectation & $20.67(6.04)$ & $20.87(6.15)$ & -0.81 & .42 \\
Respect & $3.99(1.18)$ & $4.06(1.21)$ & -1.64 & .10 \\
Make happy & $3.76(1.22)$ & $3.68(1.29)$ & 1.60 & .11 \\
Care & $3.32(1.41)$ & $3.51(1.40)$ & -3.28 & .001 \\
Greet & $3.77(1.24)$ & $3.80(1.28)$ & -0.59 & .55 \\
Obey & $3.57(1.28)$ & $3.51(1.37)$ & 1.08 & .28 \\
Financial support & $2.26(1.18)$ & $2.31(1.22)$ & -1.11 & .27 \\
Filial Piety Receipt & $22.65(4.71)$ & $20.80(5.39)$ & 8.62 & $<.001$ \\
Respect & $4.25(0.85)$ & $3.96(1.05)$ & 7.03 & $<.001$ \\
Make happy & $3.92(0.98)$ & $3.50(1.16)$ & 1.40 & $<.001$ \\
Care & $3.73(1.16)$ & $3.49(1.18)$ & 0.48 & $<.001$ \\
Greet & $4.08(0.97)$ & $3.74(1.14)$ & 7.50 & $<.001$ \\
Obey & $3.85(1.01)$ & $3.41(1.19)$ & 9.25 & $<.001$ \\
Financial support & $2.81(1.22)$ & $2.68(1.23)$ & 2.41 & .2 \\
\hline
\end{tabular}

The association between expectation of filial piety and loneliness is presented in Table 3. Expectation of filial piety was not associated with severity of loneliness after adjusting for age, sex, education, income, marital status, number of children, living arrangement, years in the U.S., years in the community, and medical co-morbidities. Living arrangement was significantly associated with loneliness in the final model $\mathrm{E}(p<.05)$. 
Table 3. Association between filial piety expectation and loneliness in older adults

\begin{tabular}{|c|c|c|c|c|c|}
\hline \multicolumn{6}{|c|}{$\begin{array}{c}\text { Outcome: Loneliness } \\
\text { Ratio of Expected Severity (95\% CI) }\end{array}$} \\
\hline & Model A & Model B & Model C & Model D & Model E \\
\hline Age & $1.02(1.01,1.03)+$ & $1.02(1.01,1.03)+$ & $1.00(0.99,1.01)$ & $1.00(0.99,1.01)$ & $1.00(0.99,1.01)$ \\
\hline Female & $1.15(0.97,1.36)$ & $1.20(1.01,1.43)^{*}$ & $0.93(0.78,1.11)$ & $0.94(0.79,1.12)$ & $0.93(0.78,1.11)$ \\
\hline Years of Education & & $1.02(1.00,1.04)^{*}$ & 1.03 (1.01,1.05)\# & 1.03 (1.01,1.05)\# & 1.03 (1.01,1.05)\# \\
\hline Married & & & $0.40(0.33,0.49)+$ & $0.40(0.33,0.49)^{+}$ & $0.41(0.33,0.50)^{+}$ \\
\hline Children alive & & & $0.97(0.91,1.03)$ & $0.97(0.91,1.03)$ & $0.97(0.91,1.03)$ \\
\hline Living arrangement & & & $0.94(0.89,0.98) \#$ & $0.94(0.90,0.99)^{*}$ & $0.95(0.90,0.99)^{*}$ \\
\hline Years in the U.S. & & & & $1.01(1.00,1.02)^{*}$ & $1.01(1.00,1.02)^{*}$ \\
\hline Years in the community & & & & $0.99(0.98,1.00)^{*}$ & $0.99(0.98,1.00)^{*}$ \\
\hline Medical Comorbidities & & & & & $1.06(0.98,1.14)$ \\
\hline
\end{tabular}

$* p<.05, \# p<.01,+p<.001$.

In contrast, lower levels of perceived filial piety receipt were associated with greater severity of loneliness (see Table 4). In the fully adjusted model (Model E), every 1 point higher in perceived filial piety receipt was associated with 0.92 times lower severity of loneliness (Ratio of Expected Sever- ity: 0.92, CI 95\%: 0.91-0.94) after all other variables were controlled. In other words, every 1 point lower in perceived filial piety receipt was associated with $8.7 \%$ greater severity of loneliness. Living arrangement was not significantly associated with loneliness in the final model $\mathrm{E}$.

Table 4. Association between perceived filial piety receipt and loneliness in older adults

\begin{tabular}{|c|c|c|c|c|c|}
\hline \multicolumn{6}{|c|}{$\begin{array}{c}\text { Outcome: Loneliness } \\
\text { Ratio of Expected Severity (95\% CI) }\end{array}$} \\
\hline & Model A & Model B & Model C & Model D & Model E \\
\hline Age & $1.02(1.01,1.03)+$ & $1.02(1.01,1.03)^{+}$ & $1.01(1.00,1.02)$ & $1.01(1.00,1.02)$ & $1.01(1.00,1.02)$ \\
\hline Female & $1.23(1.04,1.45)^{*}$ & $1.27(1.07,1.50) \#$ & $0.99(0.84,1.18)$ & $1.00(0.84,1.19)$ & $0.99(0.83,1.18)$ \\
\hline Years of Education & & $1.01(1.00,1.03)$ & $1.02(1.01,1.04) \#$ & $1.02(1.01,1.04) \#$ & $1.02(1.00,1.04)^{*}$ \\
\hline Income & & $0.90(0.83,0.97) \#$ & $0.88(0.81,0.94)^{+}$ & $0.88(0.81,0.95) \#$ & $0.88(0.81,0.95) \#$ \\
\hline Married & & & $0.41(0.34,0.50)^{+}$ & $0.41(0.34,0.50)^{+}$ & $0.42(0.34,0.51)+$ \\
\hline Children Alive & & & $0.98(0.92,1.04)$ & $0.98(0.92,1.04)$ & $0.98(0.92,1.04)$ \\
\hline Living Arrangement & & & $0.97(0.92,1.02)$ & $0.97(0.93,1.02)$ & $0.97(0.93,1.02)$ \\
\hline Years in the U.S. & & & & $1.01(1.00,1.02)$ & $1.01(1.00,1.01)$ \\
\hline Years in the Community & & & & $0.99(0.98,1.00) \#$ & $0.99(0.98,1.00) \#$ \\
\hline Medical Comorbidities & & & & & $1.06(0.98,1.13)$ \\
\hline Filial Piety Receipt & $0.92(0.91,0.94)+$ & $0.92(0.91,0.94)+$ & $0.92(0.91,0.94)+$ & $0.92(0.91,0.94)^{+}$ & $0.92(0.91,0.94)+$ \\
\hline
\end{tabular}

${ }^{*} p<.05, \# p<.01,+p<.001$.

\section{Discussion}

To our knowledge, this is the first population-based study to report the association between filial piety and loneliness in community-dwelling Chinese older adults. This study demonstrates that lower levels of perceived filial piety receipt are associated with greater severity of loneliness among Chinese older adults in the greater Chicago area after controlling for socio-demographic characteristics. While no significant association is identified between filial piety expectation and loneliness, older adults with any loneliness symptom expect more care from their children.

Our findings contribute to existing literature in many ways. First, to our knowledge, this study is among the first to examine how expectation and perceived receipt of filial piety may have influenced loneliness among the U.S. Chinese aging population. Our findings supplement the existing literature regarding associations between filial piety and depressive symptoms, life satisfaction, and suicidal ideation. Second, our study distinguished the expectation and the perceived receipt of filial piety, and assessed their associations with 
loneliness separately, through which we initiated a basic conceptual framework for a better understanding of the association between filial piety and loneliness. Third, we applied a CBPR approach and mixed recruitment strategies, which substantially helped the research team reach out to older adults with higher risk of loneliness and overcome cultural barriers associated with reporting psychological distress. Older adults were able to be interviewed by trained research assistants who can proficiently administer the questionnaire with cultural sensitivity in participants' preferred languages and dialects.

Our findings indicate lower levels of perceived filial piety receipt are associated with greater severity of loneliness adjusting for socio-demographic and medical co-morbidities. Older parents who perceive a lower level of filial piety receipt might also have infrequent interaction with adult children, thus indicating unsatisfying intergenerational relationships and higher risk of parent-child conflicts. ${ }^{[35,36]}$ Considering filial piety is often exemplified through behaviors of reciprocity, the psychological effects of receiving filial piety from children can be intensified by immigrating to the U.S., with higher perceived stress in coping with daily life, and lower self-mastery levels to confront with linguistic and cultural barriers. ${ }^{[37,38]}$ While evidence suggested that U.S. Chinese older adults primarily rely on adult children for social support, ${ }^{[18]}$ family-focused social networks are most beneficial to the well-being of older adults. ${ }^{[39,40]}$ Our finding is supported by a study indicating that decreased affection to and from children is associated with higher risk of loneliness among older adults. ${ }^{[41]}$

Our finding of the association between perceived filial piety receipt and loneliness is consistent with a prior study in mainland China, in which filial piety was identified as a protective factor against loneliness. ${ }^{[20]}$ In a qualitative study on loneliness among U.S. Chinese older adults, "children don't visit their parents" was described as "the worst scenario" of loneliness. ${ }^{[30]}$ While it is noted that lack of companionship is the most prevalent loneliness symptom among the U.S. Chinese older adults due to the family-oriented cultural value, ${ }^{[27]}$ our finding furthermore supports the idea that filial piety is an important cultural value that influences intergenerational relationships and thus, affects the psychological well-being of older adults. Future study with mixed research methodology is needed to explore the underlying mechanism to understand how perceived filial piety receipt influences the severity of loneliness.

A prior study extrapolated that older adults tend to lower their expectations of filial piety as a protective mechanism in order to avoid the disappointment with unsatisfied filial care, ${ }^{[42]}$

Published by Sciedu Press lending some support to explain why the expectation of filial piety is not significantly associated with loneliness while perceived receipt of filial piety is. Our findings yield unconventional prospects in interpreting filial piety and family care-giving practice among Chinese community. Traditionally, adult children provide filial care based on their subjective assessment of how much actual support their parents need, which excludes the opinions of older adults. Moreover, adult children may believe that filial responsibilities can be fulfilled through the use of other service entities, like paid caregivers, if adult children were incapable of performing the duties. Therefore, older parents and adult children may hold disparate perceptions on how to practice filial piety. From the perspective of Chinese older adults, children substituting filial piety duties to other persons or professionals may be considered emotionally insufficient and culturally inappropriate. Our study points out that higher levels of perceived filial piety receipt may protect older adults from loneliness irrespective of their expectation. Future study is needed to scrutinize the intrinsic and extrinsic reasons of why older adults perceive low expectations of filial piety.

Another intriguing finding of this study is that older adults with any loneliness symptoms expect higher levels of care from their children. We postulate that the higher expectation of care may function as a sign to advocate for more attention from adult children so as to cope with their feelings of loneliness. While many previous studies suggested that respect is the most or only important filial behavior to predict depressive symptoms and life satisfaction among older adults, ${ }^{[43]}$ our study reveals that each individual filial behavior may give rise to loneliness in very different patterns. Our findings call for the need to examine the association between the expectation of each filial behavior and the risk of loneliness, despite the aggregate expectation of filial piety not being associated with loneliness. For instance, the expectation of care may be consequently associated with risk of loneliness. Future study on each filial behavior can provide an in-depth understanding of the evolving conceptualization of filial piety among Chinese immigrants in U.S. and the relevant health risks associated with each filial behavior.

Furthermore, our study illustrates that cultural determinants are important in interpreting risk factors of loneliness identified in prior studies. For instance, living alone is commonly believed as an important predictor for loneliness in the U.S. population. ${ }^{[28]}$ In our study, living arrangement was significantly associated with loneliness when filial expectation and socio-demographics were controlled. However, when perceived receipt of filial piety and socio-demographics were controlled, living arrangement was no longer significantly associated with loneliness. It can be postulated that perceived 
receipt of filial piety probably explains the variations of living arrangement's effect on loneliness. Therefore, our study suggests that the negative emotions resulted from physical aloneness can be alleviated by receiving a greater amount of filial support from children. Consistent with a previous study, our finding can help explain the paradox that older immigrants may still feel lonely and isolated although they often reside with their family members and closely integrate into their kin network. ${ }^{[44]}$ Our study highlighted that rather than physical closeness, a higher level of perceived receipt of filial care represents the emotional closeness and satisfaction with interaction.

Our study has several limitations. First, although this study was representative of Chinese older adults in the greater Chicago area, it is not clear if our findings can be generalized to other Chinese populations in the U.S. or in Asian societies. Second, the receipt of filial piety is subjective, which may be biased in revealing the actual receipt of filial piety. Third, we were not able to distinguish each child since we asked participants to make an overall estimate of filial piety receipt from all of their children. Fourth, we used the aggregate score to estimate the overall filial piety expectation and receipt, and therefore we cannot specify whether each filial behavior is associated with loneliness. Fifth, the cross-sectional design cannot suggest causal relationships and future longitudinal study is necessary to provide better understanding on associations found in this study.

This research has wide implications for researchers, healthcare professionals, community organizations, and policy makers. First, this study calls for more research attention to explore how cultural values and norms can influence the psychological well-being of the aging minority population. Our findings imply that future studies of loneliness should consider incorporating perceived receipt of filial piety into the analyses. Moreover, in-depth investigation is necessary so as to specify which domain(s) of the perceived filial piety receipt may contribute to the risk of loneliness. Second, U.S. healthcare professionals need to understand filial piety and its implications on the health of Chinese older adults. While many Chinese older adults may display reluctance in selfreporting psychological distress and mental health needs, exploration of their family relationships and perception of filial piety can facilitate obtaining further information on their psychological well-being.

Third, community organizations play an important role in organizing workshops and other educational opportunities to foster a better understanding of filial piety in Chinese community. Chinese adult children may lack the opportunity to learn about filial piety from other sources through their lives in the U.S. and possess a dearth of basic understanding on 68 how perceived receipt of filial piety can influence the health of their older parents. Nurturing intergenerational communication can bridge the gap between older parents and adult children, who may have different degree of acculturation and affiliate with disparate ideologies. Fourth, policy-makers should consider the filial piety needs of Chinese older adults and incorporate cultural sensitivity when designing social services and community programs. For instance, subsidizing adult children who take over the homemakers' responsibilities in providing filial care to their parents can mitigate care-giving burden and offer incentives to practice filial piety in Chinese society.

\section{Conclusion}

In summary, our study found that lower levels of filial piety perceived receipt were associated with increased severity of loneliness among U.S. Chinese older adults in the Greater Chicago area. However, filial piety expectation was not significantly associated with loneliness. Our study may contribute to the detection of loneliness and provide suggestions for interventions geared towards reducing loneliness among the Chinese community in a culturally-sensitive approach. Future longitudinal studies are needed to explore the underlying mechanism through which perceived filial piety receipt is associated with the severity of loneliness.

\section{FUNDING INFORMATION}

Dr Dong was supported by National Institute on Aging grant (R01 AG042318, R01 MD006173, R01 CA163830, R34MH100443, R34MH100393, P20CA165588, R24MD001650 \& RC4 AG039085), Paul B. Beeson Award in Aging, The Starr Foundation, American Federation for Aging Research, John A. Hartford Foundation and The Atlantic Philanthropies.

\section{ACKNOWLEDGEMENTS}

We are grateful to Community Advisory Board members for their continued effort in this project. Particular thanks are extended to Bernie Wong, Vivian Xu, and Yicklun Mo with Chinese American Service League (CASL), Dr. David Lee with Illinois College of Optometry, David Wu with Pui Tak Center, Dr. Hong Liu with Midwest Asian Health Association, Dr. Margaret Dolan with John H. Stroger Jr. Hospital, Mary Jane Welch with Rush University Medical Center, Florence Lei with CASL Pine Tree Council, Julia Wong with CASL Senior Housing, Dr. Jing Zhang with Asian Human Services, Marta Pereya with Coalition of Limited English Speaking Elderly, Mona El-Shamaa with Asian Health Coalition.

\section{CONFLiCTS OF INTEREST Disclosure}

All authors declare no conflicts of interest in this paper.

ISSN 2377-9306 E-ISSN 2377-9330 


\section{REFERENCES}

[1] Peplau LA. Perspectives on loneliness, in Loneliness: A sourcebook of current theory, research and therapy. Wiley New York. 1982: 1-18.

[2] Donaldson JM, Watson R. Loneliness in elderly people: an important area for nursing research. Journal of advanced nursing. 1996; 24(5): 952-959. PMid:8933255 http://dx.doi.org/10.1111/j .1365-2648.1996.tb02931.x

[3] Ryan MC, Patterson J. Loneliness in the elderly. Journal of Gerontological Nursing. 1987. PMid:3648087 http://dx.doi.org/10. 3928/0098-9134-19870501-04

[4] Cacioppo JT, Hawkley LC, Ernst JM, et al. Loneliness within a nomological net: An evolutionary perspective. Journal of research in personality. 2006; 40(6): 1054-1085. http://dx.doi.org/10.10 16/j.jrp.2005.11.007

[5] Ryan MC. The relationship between loneliness, social support, and decline in cognitive function in the hospitalized elderly. Journal of gerontological nursing. 1998; 24(3): 19-27. PMid:9611553 http://dx.doi.org/10.3928/0098-9134-19980301-06

[6] Stravynski A, Boyer R. Loneliness in Relation to Suicide Ideation and Parasuicide: A Population-Wide Study. Suicide and Life-Threatening Behavior. 2001; 31(1): 32-40. PMid:11326767 http://dx.doi.o $\mathrm{rg} / 10.1521 / \mathrm{suli} .31 .1 .32 .21312$

[7] Chen Y, Hicks A, While AE. Loneliness and social support of older people in China: a systematic literature review. Health \& social care in the community. 2014; 22(2): 113-123. PMid:23714357 http://dx.doi.org/10.1111/hsc. 12051

[8] Stek ML, Vinkers DJ, Gussekloo J, et al. Is depression in old age fatal only when people feel lonely? American Journal of Psychiatry. 2005; 162(1): 178. PMid:15625218 http://dx.doi.org/10.11 76/appi.ajp.162.1.178

[9] Luanaigh CÓ, Lawlor BA. Loneliness and the health of older people. International journal of geriatric psychiatry. 2008; 23(12): 1213-1221. PMid:18537197 http://dx.doi.org/10.1002/gps . 2054

[10] Stewart M, Anderson J, Beiser M, et al. Multicultural meanings of social support among immigrants and refugees. International Migration. 2008; 46(3): 123-159. http://dx.doi.org/10.1111/j.1 468-2435. 2008.00464.x

[11] Heravi-Karimooi M, Anoosheh M, Foroughan M, et al. Understanding loneliness in the lived experiences of Iranian elders. Scandinavian journal of caring sciences. 2010; 24(2): 274-280. PMid:20210896 http://dx.doi.org/10.1111/j.1471-6712.2009.00717.x

[12] Hauge S, Kirkevold M. Older Norwegians' understanding of loneliness. International journal of qualitative studies on health and wellbeing. 2010, 5(1). http://dx.doi.org/10.3402/qhw.v5i1.46 54

[13] Weeks JR, Cuellar JB. Isolation of Older Persons: The Influence of Immigration and Length of Residence. Research on Aging. 1983; 5(3): 369-388. http://dx.doi.org/10.1177/0164027583005 003006

[14] Dai Y-T, Dimond MF. Filial piety. A cross-cultural comparison and its implications for the well-being of older parents. Journal of Gerontological Nursing. 1998; 24(3): 13-18. PMid:9611552 http://dx.doi .org/10.3928/0098-9134-19980301-05

[15] Smith CS, Hung LC. The influence of Eastern philosophy on elder care by Chinese Americans attitudes toward long-term care. Journal of Transcultural Nursing. 2012; 23(1): 100-105. PMid:22228782 http://dx.doi.org/10.1177/1043659611423827

[16] Kim O. Predictors of loneliness in elderly Korean immigrant women living in the United States of America. Journal of Advanced Nursing.
1999; 29(5): 1082-1088. PMid:10320490 http://dx.doi.org/1 $0.1046 / j .1365-2648.1999 .00993 . x$

[17] Wong ST, Yoo GJ, Stewart AL. Examining the types of social support and the actual sources of support in older Chinese and Korean immigrants. The International Journal of Aging and $\mathrm{Hu}-$ man Development. 2005; 61(2): 105-121. PMid:16161288 http: //dx.doi.org/10.2190/AJ62-QQKT-YJ47-B1T8

[18] Chen R, Simon MA, Chang ES, et al. The Perception of Social Support Among US Chinese Older Adults Findings From the PINE Study. Journal of aging and health. 2014; 26(7): 1137-1154. PMid:25239970 http://dx.doi.org/10.1177/0898264314529332

[19] Hawkley LC, Hughes ME, Waite LJ, et al. From social structural factors to perceptions of relationship quality and loneliness: the Chicago health, aging, and social relations study. The Journals of Gerontology Series B: Psychological Sciences and Social Sciences. 2008; 63(6): S375-S384. PMid:19092047 http://dx.doi.org/10.1093/ger onb/63.6.S375

[20] Yang K, Victor CR. The prevalence of and risk factors for loneliness among older people in China. Ageing and Society. 2008; 28(03): 305-327. http://dx.doi.org/10.1017/S0144686X07006848

[21] Simon MA, Chen R, Chang ES, et al. The Association Between Filial Piety and Suicidal Ideation: Findings From a CommunityDwelling Chinese Aging Population. The Journals of Gerontology Series A: Biological Sciences and Medical Sciences. 2014; 69(Suppl 2): S90-S97. PMid:25378454 http://dx.doi.org/10.1093/g erona/glu142

[22] Dong X, Chang ES, Wong E, et al. A qualitative study of filial piety among community dwelling, Chinese, older adults: Changing meaning and impact on health and well-being. Journal of Intergenerational Relationships. 2012; 10(2): 131-146. http://dx.doi.org/10.10 $80 / 15350770.2012 .673393$

[23] Bureau UC. American Community Survey. Washington: US Census Bureau. 2010.

[24] Kuo BC, Roysircar G. Predictors of acculturation for Chinese adolescents in Canada: Age of arrival, length of stay, social class, and English reading ability. Journal of Multicultural Counseling and Development. 2004; 32(3): 143-154. http://dx.doi.org/10.1002 /j.2161-1912.2004.tb00367.x

[25] Mui AC, Shibusawa T. Asian American elders in the twenty-first century: Key indicators of well-being. Columbia Univ Pr. 2008.

[26] Dong X, Zhang M, Simon MA. The expectation and perceived receipt of filial piety among Chinese older adults in the Greater Chicago area Journal of aging and health. 2014; 26(7): 1225-1247. PMid:25239974 http://dx.doi.org/10.1177/0898264314541697

[27] Simon MA, Chang ES, Zhang M, et al. The Prevalence of Loneliness Among US Chinese Older Adults. Journal of aging and health. 2014; 26(7): 1172-1188. PMid:25239972 http://dx.doi.org/10.11 $77 / 0898264314533722$

[28] Theeke LA. Predictors of loneliness in US adults over age sixty-five. Archives of psychiatric nursing. 2009; 23(5): 387 396. PMid:19766930 http://dx.doi .org/10.1016/j . apnu. 20 08.11 .002

[29] Wilson C, Moulton B. Loneliness among older adults: A national survey of adults 45+. Washington, DC: AARP. (Special report). In Knowledge networks and insight policy research. 2010.

[30] Dong X, Chang ES, Wong E, et al. Perception and negative effect of loneliness in a Chicago Chinese population of older adults. Archives of gerontology and geriatrics. 2012; 54(1): 151-159. PMid:21621865 http://dx.doi.org/10.1016/j.archger.2011.04.022 
[31] Dong X, Wong E, Simon MA. Study design and implementation of the PINE study. Journal of aging and health. 2014: 0898264314526620. http://dx.doi.org/10.1177/089826431 4526620

[32] Dong X, Chang ES, Wong E, et al. Working with culture: lessons learned from a community-engaged project in a Chinese aging population. Aging Health. 2011; 7(4): 529-537. http://dx.doi.org/1 $0.2217 /$ ahe 11.43

[33] Simon MA, Chang ES, Rajan KB, et al. Demographic Characteristics of US Chinese Older Adults in the Greater Chicago Area Assessing the Representativeness of the PINE Study. Journal of aging and health. 2014; 26(7): 1100-1115. PMid:25239968 http: //dx.doi.org/10.1177/0898264314543472

[34] Gallois C, Giles H, Ota H, et al. Intergenerational communication across the Pacific Rim: The impact of filial piety., in Latest contribution to cross-cultural psychology. Lisse, Netherlands: Swets \& Zeitlinger. 1996.

[35] Lawrence RH, Bennett JM, Markides KS. Perceived intergenerational solidarity and psychological distress among older Mexican Americans. Journal of Gerontology. 1992; 47(2): S55-S65. PMid:1538076 http://dx.doi.org/10.1093/geronj/47.2.S55

[36] Yeh KH, Bedford O. Filial belief and parent-child conflict. International Journal of Psychology. 2004; 39(2): 132-144. PMid:22587548 http://dx.doi.org/10.1080/00207590344000312

[37] Dong X, Zhang M, Simon MA. Self-mastery among Chinese Older Adults in the Greater Chicago Area. AIMS Medical Science. 2014;
1(1): 57-72. http://dx.doi.org/10.3934/medsci.2014.1.5 7

[38] Zhang M, Simon MA, Dong X. The Prevalence of Perceived Stress among US Chinese Older Adults. AIMS Medical Science. 2014; 1(1): 40-56. http://dx.doi.org/10.3934/medsci.2014.1.40

[39] Cheng S-T, Lee CKL, Chan ACM, et al. Social network types and subjective well-being in Chinese older adults. The Journals of Gerontology Series B: Psychological Sciences and Social Sciences. 2009: gbp075. http://dx.doi.org/10.1093/geronb/gbp075

[40] Phillips DR, Siu OL, Yeh AGO, et al. Informal social support and older persons' psychological well-being in Hong Kong. Journal of cross-cultural gerontology. 2008; 23(1): 39-55.

[41] Mancini JA, Blieszner R. Aging parents and adult children: Research themes in intergenerational relations. Journal of Marriage and the Family. 1989: 275-290. PMid:18228121 http://dx.doi.org/10. 1007/s10823-007-9056-0

[42] Dai Y-T. The effects of family support, expectation of filial piety, and stress on health consequences of older adults with diabetes mellitus. 1995. http://dx.doi.org/10.2307/352492

[43] Cheng ST, Chan AC. Filial piety and psychological well-being in well older Chinese. The Journals of Gerontology Series B: Psychological Sciences and Social Sciences. 2006; 61(5): P262-P269. http://dx.doi.org/10.1093/geronb/61.5.P262

[44] Treas J, Mazumdar S. Older people in America's immigrant families: Dilemmas of dependence, integration, and isolation. Journal of Aging Studies. 2002; 16(3): 243-258. http://dx.doi.org/10.1016/S 0890-4065(02) 00048-8 